\title{
Hume e a Recusa do Estado de Natureza,
}

\section{Esboço de Duas Críticas.}

\author{
Andréa Cristina Silva (Bolsista PIBIC/CNPq) \\ Orientadora: Maria das Graças de S. Nascimento
}

"Confessam que a justiça reside nas leis naturais conhecidas em todos os países (...) Há sem dúvida leis naturais; mas essa bela razão corrompida corrompeu tudo:(...) Dessa confusão resulta que um diz que a essência da justiça é a autoridade do legislador; outro, a comodidade do soberano;outro o costume presente, e é o mais certo: nada, segundo sua razão, é justo em si; tudo se abala com o tempo. O costume faz toda a eqüidade, unicamente por ser admitido; é o fundamento místico da autoridade." Pascal. Pensée. Fragmento 294

O último dos ensaios políticos publicados por Hume entitula-se "Da origem do Governo"1 Neste texto David Hume nos diz: "o homem nasce em uma família e é obrigado a conservar a sociedade por necessidade, por inclinação natural e por hábito"2 A partir dessa afirmação, cabe notar a intenção de Hume em salientar o caráter natural da sociedade humana, se bem que podemos distingüir a sociabilidade absolutamente instintiva oriunda de um principio primeiro e original do homem: que seria o apetite sexual ${ }^{3}$ gerador da família; e uma sociabilidade essencialmente política, proveniente da necessidade de conservação daquela comunidade familiar.

Para Hume a sociedade política é resultado de uma certa evolução, o homem é levado a instituir a sociedade política, tornando assim, possível a administração da justiça, única garantia da paz, da segurança e das relações mútuas entre os homens $^{4}$ É necessário então, para que o homem seja capaz de se diferenciar do restante dos outros animais, de instituir e fazer uso da justiça. Dizemos isso porque para Hume o "homem é de todos os animais o mais carente, o mais inferior, e que só a sociedade lhe supri as carências e lhe dá superioridade" 5 num limite podemos dizer que o homem não sobreviveria sem uma associação, além disso, como dito no ensaio acima citado, "os homens são freqüentemente distraidos de seus principais interesses, os mais importantes e longinquos, pela sedução de tentaçōes presentes, embora muitas vezes insignificantes. Esta grande fraqueza é incurável na natureza humana"

Curiosamente, a investigação de Hume nos leva à constatação de um desvio humano em relação aos seus interesses maiores e mais importantes em virtude de 
prazeres corriqueiros e imediatos. Hume parece atribuir um lado negativo à natureza humana, mas por que afirmar um desvio da natureza humana em relação aos seus verdadeiros interesses? Onde Hume se afastaria de Hobbes se levarmos em conta a afirmação do Leviatã ( cap. xvii) de que as paixões naturais dos homens só podem ser equilibradas com o respeito ao cumprimento das leis de natureza, ou seja, a busca pela paz e o cumprimento do pacto que institui o Estado? ${ }^{6}$

Se é a administração da justiça a única possibilidade de se fazer conservar a sociedade entre os homens, cabe buscar conhecer um pouco mais sobre a justiça. $E$ é na Investigação Sobre os Princípios da Moral ${ }^{7}$ conhecida como a segunda Investigação, no capítulo referente à Justiça, que Hume afirma: "se todas as pessoas tivessem suficiente sagacidade para perceber, em todas as ocasiões, o grande benefício associado à observância da justiça e da imparcialidade, e suficiente força espiritual para manter um constante apego a um interesse de caráter mais geral e remoto em oposição às seduções do prazer imediato e vantagens de curto prazo, não haveria, nesse caso, nada de semelhante a um governo ou uma sociedade politicamente organizada, mas cada pessoa, seguindo sua liberdade natural, viveria em completa paz e harmonia com todos os demais" É interessante notar que essa citação vem complementar aquela passagem do ensaio que acentua a "fraqueza humana" com a diferença de que aqui Hume parte de uma possivel "força espiritual" dos homens que os capacitaria a perceber a grande utilidade do uso da justiça sem uma sociedade politicamente organizada. Nesse sentido cabe perguntar o que constitui uma sociedade politicamente organizada?

Ao que parece Hume propõe uma investigação sobre o político em meio a dois extremos, quer dizer, o político é o que se dá diante da fraqueza humana de não sobreviver sem associação e da necessidade de uma possível força espiritual para que possa realizar, ou melhor, manter a associação que Ihe é originária.

É ainda na Segunda Investigação que, para melhor ilustrar a verdadeira fonte da justiça, Hume nos leva a um exercício da imaginaçăo, nos faz supor uma sociedade em que todo indivíduo se achasse completamente provido de tudo aquilo que seus mais vorazes apetites pudessem necessitar Em condição tão afortunada, diz Hume, todas as demais virtudes sociais iriam florescer e se intensificar; mas, quanto à virtude da justiça, dela não se ouviria falar uma vez sequer. Qual o propósito de efetuar a repartição de bens quando todos já tem mais do que suficiente? FORTUNA

Além dessa suposição Hume nos sugere outra, que em lugar das carências e fraquezas humanas o homem fosse dotado de uma força espiritual repleta de sentimentos amigáveis e generosos para com todos os outros seres humanos. Nesse caso de grandeza de espírito, jamais se cogitaria as divisões e barreiras da propriedade e obrigação. Porque erigir marcos limítrofes entre o meu campo e o do meu vizinho se meu coração não faz nenhuma divisão entre nossos interesses? BENEVOLÊNCIA

Em contraponto, somos levados, de um lado, a pensar na escassez em oposição à abundância. E por outro, a pensar no egoísmo em oposição à benevolência. No caso de carência extrema de meios para a sobrevivência, "seria por ventura um crime, após um naufrágio, agarrar-se a qualquer meio ou instrumento de salvação em que se pudesse por as mãos, sem preocupar-se com as anteriores limitaçōes 
decorrentes do direito de propriedade? Cada homem, neste caso, não estaria livre para zelar por si próprio empregando todos os meios que bem entendesse?" CARÊNCIA.

Por outro lado Hume supõe um estado de guerra. Nesta condição a virtude da justiça não teria qualquer uso ou vantagem para as partes belicantes, seu uso estaria suspenso. "O poder seria a única medida do direito, e uma guerra permanente de todos contra todos seria o resultado do egoísmo incontrolado e da barbárie dos homens" EGOíSMO.

O que Hume nos sugere com estes argumentos é que nas situações em que há extrema abundância ou benevolência, extrema miséria ou egoismo não se pode constatar o uso da virtude da justiça. A justiça deve sua origem e existência à utilidade que proporciona ao público, portanto, qualquer teoria que procure explicar a origem da sociedade e a necessidade da justiça, a partir de tais princípios, estaria fadada a um erro de princípio.

Não seria essa a intenção de Hume ao comparar a ficção poética de uma idade de ouro ${ }^{8} \mathrm{com}$ a ficção filosófica de um Estado de natureza? A recusa dessas ficções parece ser um ponto fundamental para se pensar a crítica de Hume às teorias que recorrem à idéia de um estado de natureza. E essa crítica pode ser desdobrada, salienta dois pontos para discussão. O primeiro é propriamente uma discussão com os contratualistas. Não é o contratualismo que recorre à suposição de que o indivíduo se encontraria num estado de natureza, estado este que daria origem a uma sociedade política organizada por meio de um pacto ou contrato?

O absurdo dessa teoria seria, aos olhos de Hume, o de pressupor a existência de um estado de natureza como ponto de partida para a explicação da sociedade, postular tal princípio seria um equívoco. O homem nasce num ambiente familiar, e o que o leva à instituição da justiça não é uma postulação de ordem divina, metafísica, ou puramente racional, o que leva os homens a instituirem a justiça é um sentido comum, uma consciência de que só a administraçāo da justiça garante paz e ordem assim como as relações mútuas. Para Hume a "necessidade da justiça para a subsistência da sociedade é o único fundamento dessa virtude, e como nenhuma qualidade moral é mais valorizada do que ela, podemos concluir que esta característica de utilidade é, de modo geral, a mais enégica, porque o uso e o fim da justiça é proporcionar felicidade, segurança e ordem na sociedade ${ }^{9}$

Se é o interesse que dá origem à sociedade politicamente organizada, esse interesse tem sua fonte no que é útil ou não, "o homem é naturalmente movido pelo desejo de buscar o seu prazer e evitar o desprazer" E essa é uma questão de fato, é na observância das ações que se dá a origem da aprovação e da desaprovação, do louvor ou da censura, ou seja, é no âmbito da experiência, das sensações humanas que se origina as relações morais e também a diferenciação do justo e do injusto. Com isso Hume quer dizer que o julgamento moral não pode ser fundado somente na razão, que também tem seu papel como uma razão experimental, mas é no nível das paixões humanas, do sentimento, que podemos dizer que uma ação é útil ou não.

Além disso caberia ainda perguntar, qual é, então, a natureza da convenção que estabelece a justiça? Quer dizer, como se dá a idéia de justiça no espírito humano? 
À moda de Pascal, Hume dirá que não há justo em si, que tudo se abala com o tempo e que o meu, o teu, o nosso, é obra de convenção. Não é isso que foi salientado ali no apêndice III da Investigação? Que a justiça é originada através de uma convenção entre os homens? Mas que só podemos dizer que a justiça é uma convenção se convenção for entendida não como uma promessa, mas como um interesse comum, um sentimento que cada qual experimenta em seu próprio peito, que observa em seus companheiros e que o leva, em colaboração com outros, a estabelecer um plano ou sistema geral de ações que tende à utilidade pública? Afirmar que a justiça surge de uma promessa seria um absurdo completo, promessas são posteriores à idéia de justiça, além disso, qualquer promessa pode ser quebrada ${ }^{10}$. A idéia de justiça surge de um interesse comum, assim como existe convenção no uso da linguagem, e no uso do ouro e da prata como medidas de valor. $E$ dentro desse interesse comum que se estabelece os direitos e deveres dos homens.

E esse é justamente o segundo ponto ao qual somos levados a pensar quando da recusa humeana da aberrante ficção filosófica de um estado de natureza, pensamos na recusa, num plano mais geral e externo à filosofia humeana de qualquer idéia de direito natural, com isso Hume se afasta de toda a tradição jusnaturalista e do debate que se encerrava no século XVIII de que a idéia de justiça é advinda de uma razão natural. Hume recusa a lei divina, recusa a lei natural, recusa uma lei racional. Os direitos são, ao que parece, frutos do costume, do hábito, convenções humanas e não inatos.

Por isso a justiça é estabelecida segundo sua utilidade em concordância com os interesses dos homens, em outras palavras, a sociabilidade essencialmente política pode ser representanda pela escolha do homem ao que the é preferivel ou não, isso equivale a dizer que a sociedade política não liberta o homem de um estado de caos $^{11}$ para um estado social, civilizado.

Grosso modo, podemos dizer que, e conforme Simone Goyard-Fabre no texto Hume et la Critique du Contrat Sociale ${ }^{12}$, Hume não confunde o ponto de vista do fato com o ponto de vista do direito. De fato a origem do governo se dá através do interesse e da utilidade, essa origem é verificável, pertence ao espetáculo das coisas humanas $^{13}$ é pela veia da empiria que se verifica a origem de fato de governo. 0 governante seria aquele que buscaria a parcialidade, o equilíbrio entre os interesses e as paixões dos homens. E a questão do direito é a de saber como conciliar os interesses particulares de cada um aos da sociedade como um todo, como equilibrar as paixões de satisfação imediata com os interesses maiores, e ainda de como fazer prevalecer o interesse geral e nāo o interesse do governante.

De um modo bastante geral estas são algumas das questões que merecem um tratamento em relação a crítica de Hume ao contratualismo:

1 Numa análise comparativa, estabelecer uma relação da teoria humeana sobre a origem do governo com a tradição jusnaturalista, buscando entender qual o significado da afirmação de Hume de que a justiça tem um caráter de convenção e não de promessa. (Grotius e Pufendorf)

2 Numa análise mais interna do próprio pensamento humeano:

a) buscar a compreensão do papel das paixões nas questões morais, isso levando-se em consideração a teoria hobbesiana. Quer dizer, onde Hume se afasta de 
Hobbes, se ambos afirmam a existência de paixões que desvirtuam o homem na busca de seus objetivos ${ }^{14}$.

E ainda, e isso não foi dito aqui procurar discutir Hume diretamente com a teoria lockeana presente no Segundo Tratado Sobre o Governo que, no XVIII era uma das teorias mais influentes e que com certeza, parece ter influenciado fortemente Hume no que se refere a relação entre justiça e propriedade, em todos os exemplos usados por Hume nas suposições de uma sociedade sem justiça, fala-se, em letra, de uma não diferenciação entre o meu e o teu, nesse sentido Hume parece vincular justiça e propriedade, mas até que ponto podemos dizer isso se levarmos em conta a teoria de Locke de que o Estado seria apenas uma instituição que vem assegurar aquilo que é meu, ou seja, corpo bens e a liberdade?

\section{NOTAS}

1. Cf. Simone Goyard-Fabre em seu texto Hume et la Critique du Contrat Social

2. Coleção Os Pensadores, trad: João Paulo Monteiro e Armando Mora D'Oliveira. p.230.

3. Tratado na Natureza Humana.(S.B.) Livro III, Parte 2, Seção 2. p.486

4. A idéia de uma sociedade política oriunda da família sem a recorrência de um estado de natureza remete aos antigos (Aristóteles, Livro I A Política). Nesse sentido, observamos o seguinte: Hume parece estar mais próximo dessa concepção clássica de Estado, em que não há dicotomia nem oposição de um estado pré-político para um estado essencialmente político, e sim uma espécie de continuidade. Bobbio no texto Thomas Hobbes ( cap 1 p. 11 O Modelo Jusnaturalista Ed. Campus) afirma que há uma dicotomia presente no modelo clássico de estado: ou seja, família/ Estado, e que esta mesma dicotomia se exprime também no modelo moderno como estado de natureza/estado civil. Particularmente pensamos que, na verdade não há dicotomia em nenhum dos dois modelos, o que parece é que há uma continuidade ou evolução no primeiro caso ( modelo clássiso) e uma oposição no segundo caso (modelo moderno). Isso porque o estado de natureza não cabe no estado político, um exclue o outro, existe uma oposição completa de um em relação ao outro, principalmente em Hobbes.

5. T.N.H. Ibid.

6. Seria interessante perguntar que tipo de paixão conduz o homem ao interesse que Ihe útil e qual o papel da razão no consentimento do uso da justiça. $E$ isso nos remete a questão do amor a si mesmo tão presente em Hobbes quanto em Hume. Qual paixão teria maior peso na realização do interesse, o egoísmo ou a benevolência? Como fazer coincidir os interesses individuais com o interesse público?

7. Hume, D., Uma Investigação Sobre os Principios da Moral.Trad.José Oscar de Almeida Marques, Campinas, SP,. Editora da UNICAMP,1995. p. 35.

8. Tempo poético em que os rios davam leite, os carvalhos mel e que não havia tempestades nem na natureza, nem no coração dos homens.

9. Idem. p. 63.

10. Vale a pena lembrar Hobbes, para o cumprimento da palavra é preciso o uro 
da espada, quer dizer, a soberania é que garante o estado, e não o pacto por si mesmo.

11. João Paulo Monteiro. Teoria, Retórica e Ideologia. p 111. Ed. Ática.

12. Simone Goyard-Fabre, "Hume et la Critique du Contrat Sociale, esquisse d'une thérie de l'institution". Ruvue de Metaphysique et de Morale. no 3. 1988.

13. A expressão é de Voltaire.

14. Leviatã. Cap. XVII. 